\title{
MLL-SEPT6 Positive Acute Myeloid Leukemia Patients Often Co-occur With NRAS Mutations?
}

Fang Chen

Shengjing Hospital of China Medical University

Ying Yang

Shengjing Hospital of China Medical University

Shuang Fu ( $\boldsymbol{\nabla}$ coolerfspretty@126.com )

Shengjing Hospital of China Medical University https://orcid.org/0000-0002-9005-5982

\section{Research}

Keywords: Gene rearrangement, Acute myeloid leukemia, MLL-SEPT6, Mutation, NRAS

Posted Date: November 8th, 2021

DOI: https://doi.org/10.21203/rs.3.rs-997347/v1

License: () (i) This work is licensed under a Creative Commons Attribution 4.0 International License. Read Full License 


\begin{abstract}
Background

The MLL-SEPT6 fusion gene is a relatively rare genetic event in leukemia. Its clinical characteristics, prognosis, especially the profile of co-occurring gene mutations remain unclear.
\end{abstract}

\title{
Methods
}

We retrospectively analyzed four rare leukemia cases carrying MLL-SEPT6 in our hospital from laboratory examination, diagnosis, treatment and prognosis, and provided a comprehensive and detailed description on clinical profile of MLL-SEPT6-positive AML patients in the literature.

\section{Results}

All the four patients were diagnosed with acute myeloid leukemia (AML) and harbored $\mathrm{X}$ chromosome and 11 chromosome rearrangements. Three of four cases occurred NRAS mutation while the rest one with congenital AML did not. Of the four cases, one developed drug-resistant, one suffered relapse after bone marrow transplantation (BMT) and one died. Combined with other cases reported in literatures, we found that of all patients diagnosed with AML, $90.9 \%$ were children ( $\leq 9$ years old) and $54.5 \%$ were infants ( $\leq 1$ year old). The survival time between infant group ( $\leq 1$ year old) and pediatric group $(>1$ and $<18$ years old), patients that received BMT and that received chemotherapy alone did not show significant differences $(P>0.05)$.

\section{Conclusions}

MLL-SEPT6 was more commonly observed in pediatric AML patients, some of which may co-occur with NRAS mutations. The prognosis was inconclusive and may not be related to age or BMT. More information needs to be accumulated and summarized from additional cases to confirm the underlying connection between NRAS mutations and MLL-SEPT6 in order to better understand the profile in MLL-SEPT6-positive AML.

\section{Background}

Acute myeloid leukemia (AML) is a malignant tumor that originates from the myeloid blood cells, characterized by abnormally increased leukemic cells in bone marrow or peripheral blood [1]. Cytogenetic and molecular abnormalities occur commonly in AML patients. Based on genetic mutations and specific chromosomal rearrangements, the World Health Organization (WHO) divides AML with recurrent genetic abnormalities into 11 subgroups [2]. The mixedlineage leukemia $(M L L)$ gene rearrangements is one of the most common chromosomal abnormalities in AML $[3,4]$.

The $M L L$ gene at 11q23 has many partner genes, of which over 80 have been identified [5]. Among them, the SEPTIN6 (SEPT6) gene located at Xq24 involving in the formation of MLL arrangement $t(X ; 11)(q 22-24 ; q 23)$ is extremely rare in AML [6], a limited number of cases have been documented in literatures. To our knowledge, most cases are children while only one adult case has been reported [6-16]. The exact role of MLL-SEPT6 in hematopoietic cells and its effect on leukemogenesis are still unknown. There is little information on clinical features, treatment strategies and prognosis of such patients, accompanied gene mutations carried by such patients have not been described.

We retrospectively analyzed data on four acute leukemia patients carrying the MLL-SEPT6 fusion gene that treated in our hospital, especially of the gene mutations information. Additionally, we reviewed cases in literatures together with our cases to provide evidence for potential therapeutic strategies.

\section{Materials And Methods}

\section{Case selection}

We collected four patients harboring MLL-SEPT6 gene from a pool of 1656 leukemia patients within our hematological diseases database in the past four years, which were referred as case 1-4. The diagnostic criteria were according to WHO classification of tumors of haematopoietic and lymphoid tissues [17]. We conducted a retrospective analysis and systematic summary with information of morphology, flow cytometric analysis, cytogenetics, molecular biology and other related laboratory tests results.

\section{Literature review}

We conducted literature search on PubMed with the keywords "MLL-SEPT6", "MLL-SEPTIN6" or "t(X;11)" to gather related case reports.

\section{Statistical Analysis}

Kaplan-Meier method was used for survival evaluation. Log-rank test was used to assess the difference between groups. P $<0.05$ was considered statistically significant. All data were analyzed with SPSS Statistics, version 21 (StatSoft).

\section{Results}

\section{Clinical presentation}


All MLL-SEPT6 positive cases (case 1-4) were male with ages ranging from 0 to 57 years and a median of 5.2 years, their detailed information was summarized in Table 1. All cases had manifestations of fever and pale complexion. The three pediatric cases (cases 2,3 , and 4 ) were accompanied by hepatosplenomegaly, and two cases (cases 3 and 4) had scattered petechiae and ecchymoses. The case 1 is an elderly male patient with perianal abscess and diabetes in addition to the above symptoms. The case 2 was accompanied by pain in both lower limbs, tenderness of the sternum and hypertrophy of tonsils. In the case 3, multiple lymph nodes were palpable on bilateral neck, he was positive of sternal tenderness, he also had hyperuricemia and acute bronchial pneumonia. The case 4 is a newborn delivered by cesarean section due to "decreased fetal heart rate". The birth weight was $3100 \mathrm{~g}$. The infant had no spontaneous breath at birth and was generally cyanotic, he restored spontaneous respiration under assisted ventilation, he developed persistent pulmonary arterial hypertension and neonatal pneumonia. His parents were healthy and with no history of genetic disease.

Table 1

Clinical features of 4 cases of AML patients with MLL-SEPT6 positive

\begin{tabular}{|c|c|c|c|c|}
\hline Items & Case 1 & Case 2 & Case 3 & $\mathrm{Ca}$ \\
\hline Sex & Male & Male & Male & Mi \\
\hline Age & 57 years & 9 years & 16 months & $0 \mathrm{r}$ \\
\hline $\begin{array}{l}\text { Physical } \\
\text { examination }\end{array}$ & Perianal abscess & $\begin{array}{l}\text { Lower limbs pain, sternal } \\
\text { tenderness and tonsil hypertrophy }\end{array}$ & $\begin{array}{l}\text { Scattered petechiae on the neck, cervical } \\
\text { lymphadenopathy and sternal tenderness } \\
(+)\end{array}$ & $\begin{array}{l}\text { Sc } \\
\text { pe } \\
\text { ec }\end{array}$ \\
\hline $\begin{array}{l}\text { Hepatomegaly/ } \\
\text { Splenomegaly }\end{array}$ & No/No & Yes/Yes & Yes/Yes & Ye \\
\hline CNS involvement & No & Yes & No & Nc \\
\hline $\begin{array}{l}\text { WBC/Hb/PLT } \\
\left(\times 10^{9} / \mathrm{L} / \mathrm{g} / \mathrm{L} /\right. \\
\left.\times 10^{9} / \mathrm{L}\right)\end{array}$ & $12.3 / 79.0 / 105.0$ & $3.0 / 93.0 / 245.0$ & $123.8 / 41.0 / 39.0$ & 11 \\
\hline Serum LDH (U/I) & NA & 966 & 2080 & $\mathrm{~N} f$ \\
\hline $\begin{array}{l}\text { D-Dimer } \\
\text { (ug/L(DDU)) }\end{array}$ & 13117.0 & 3149.0 & 2469.0 & 62 \\
\hline Blood blasts (\%) & 69.0 & 2.0 & 52.0 & 17 \\
\hline $\begin{array}{l}\text { Bone marrow } \\
\text { blasts (\%) }\end{array}$ & 92.0 & 27.5 & 56.0 & 20 \\
\hline $\begin{array}{l}\text { Morphological } \\
\text { diagnosis }\end{array}$ & AML-M5 & AML-M2 & AML-M4 & Al \\
\hline Immunophenotype & $\begin{array}{l}\text { The leukemic cells expressed HLA-DR, } \\
\text { CD117, CD33, CD13, CD38, CD15, CD64 } \\
\text { and CD4 }\end{array}$ & $\begin{array}{l}\text { The leukemic cells expressed HLA- } \\
\text { DR, CD 33, CD38, CD15, CD 64 and } \\
\text { CD4 }\end{array}$ & $\begin{array}{l}\text { The leukemic cells expressed HLA-DR, } \\
\text { CD 33, CD13, CD38, CD15 and CD } 64\end{array}$ & $\begin{array}{l}\text { Th } \\
\text { ce } \\
\mathrm{HL} \\
\mathrm{CL} \\
\text { an }\end{array}$ \\
\hline Karyotype & $46, \mathrm{Y}, \mathrm{t}(\mathrm{X} ; 11)(\mathrm{q} 24 ; \mathrm{q} 23)[4] / 46, \mathrm{XY}[6]$ & $\begin{array}{l}\text { 45,Y,del(X)(q21),der(11)t(X;11) } \\
\text { (q24;q23),-20,add(22)(q13)[3] }\end{array}$ & $\begin{array}{l}\text { 46, Y, t(X;11)(q24;q23), del(7)(q21q31) } \\
{[13] / 46, X Y[2]}\end{array}$ & 46 \\
\hline Gene mutations & $\begin{array}{l}\text { NRAS: NM_002524:exon2:c.G35T:p.G12V } \\
\text { rs121913237, VAF = 0.0369; ASXL1: } \\
\text { NM_015338:exon12:c.2464dupA:p.D821fs, } \\
\text { VAF =0.3585 }\end{array}$ & $\begin{array}{l}\text { NRAS: } \\
\text { NM_002524:exon2:c.G35T:p.G12V } \\
\text { rs121913237, VAF }=0.0300\end{array}$ & $\begin{array}{l}\text { NRAS:NM_002524:exon4:c.G436A:p.A146T, } \\
\text { VAF }=0.4411\end{array}$ & $\mathrm{~N} \epsilon$ \\
\hline $\begin{array}{l}\text { Treatment } \\
\text { protocol }\end{array}$ & $\begin{array}{l}\text { IA regimen (resistance); then changed to } \\
\text { decitabine combined with half-dose CAG } \\
\text { regimen (once) + high dose cytarabine }\end{array}$ & $\begin{array}{l}\text { MAE regimen + intrathecal } \\
\text { chemotherapy + BMT }\end{array}$ & HA regimen & $\begin{array}{l}\text { Nc } \\
\text { ch }\end{array}$ \\
\hline CR & Yes & Yes & Yes & $\mathrm{N} f$ \\
\hline Follow-up (mo) & 9 & 38 & 34 & $0 . t^{2}$ \\
\hline Outcome & Alive & Alive & Alive & Dir \\
\hline
\end{tabular}

Footnotes: CNS, central nervous system; WBC, white blood cells; Hb, hemoglobin; PLT, platelets; LDH, lactate dehydrogenase; VAF, variant allele frequencies; I + cytosine arabinoside; CAG, cytarabine + aclacinomycin + granulocyte colony stimulating factor; MAE, Mitoxantrone + cytarabine + etoposide; BMT, bone má transplantation; HA, homoharringtonine + cytarabine; CR, complete remission; mo, month; NA, not available.

Laboratory results showed that three cases (cases 1, 3, and 4) had high white blood cells (WBC) count, anemia, and low platelet count. One case (case 2) had low level of hemoglobin and WBC count but normal platelet count, and two cases (case 2 and 3 ) had increased level of serum lactate dehydrogenase. The Ddimer level of all four patients were increased. 
All cases exhibited morphological characteristics of AML (Figure 1). The French American British (FAB) morphological classification of each case was M5 (case 1 and 4), M2 (case 2) and M4 (case 3). Three cases (cases 1, 3, and 4) showed hypercellular bone marrow and the other case (case 2) had severe hypocellular bone marrow. The case 1 and case 4 were evaluated as M5 and revealed of $92.0 \%$ and $20.4 \%$ blasts in marrow aspirate, $69.0 \%$ and $17.0 \%$ in peripheral blood respectively (Table 1, Figure 1A and 1D). The case 2 was evaluated as M2, the marrow aspirate revealed $27.5 \%$ myeloblasts and the peripheral blood exhibited $2.0 \%$ blasts (Table 1, Figure 1B). The case 3 was evaluated as M4, the marrow aspirate showed $56.0 \%$ blasts and the peripheral blood exhibited $52.0 \%$ blasts (Table 1, Figure 1C).

\section{Flow cytometric analysis}

The flow cytometric analysis revealed the presence of myeloid blasts in bone marrow samples from all four patients (Table 1, Figure 2). The percentage of blasts was highest of $92 \%$ in the case 1 and lowest of $4.2 \%$ in the case 3 . All cases were positive for CD33, CD15, CD64 indicating myeloid lineage, CD 13 was positive only in the case 1 and case 2 . All the cases were positive for CD38 and HLA-DR. CD117 was positive only in the case 3 , CD34 was negative in all the four cases.

\section{Cytogenetic analysis}

The results showed that all four cases had clonal abnormalities of $\mathrm{X}$ chromosome and chromosome 11 or complex karyotype abnormalities (Table 1 , Figure $3)$. In case 1 , the metaphase cells exhibited abnormalities of $t(X ; 11)(q 24 ; q 23)$ (Figure 3A). The metaphase cells collected in the case 2 showed 45 , $Y$, del $(X)$ (q21), $\operatorname{der}(11) t(X ; 11)(q 24 ; q 23),-20$, add(22)(q13) (Figure 3B). In the case 3, in addition to the abnormal karyotype of $t(X ; 11)(q 24 ; q 23)$, thirteen metaphase cells had del(7)(q21q31) (Figure 3C). The metaphase cells in case 4 showed abnormal karyotype of 46, Y, ins(X;11)(q23;q24q12) (Figure 3D).

\section{Molecular analysis}

We performed molecular biology tests including screening of fusion genes and next-generation sequencing (NGS) analysis on all cases (Table 1). The MLLSEPT6 fusion gene was detected in all four cases. The NGS panel included a total of 20 frequently mutated genes in AML which were ASXL1, CEBPA, DNMT3A, EZH2, FLT3, IDH1, IDH2, KIT, NPM1, PHF6, RUNX1, TET2, TP53, BCOR, GATA2, MLL, KRAS, NRAS, PDGFRA and WT1, the sequencing depth was 2000x. The results showed that three cases (cases 1-3) harbored NRAS (NM_002524) mutations, the mutation sites of the case 1 and 2 were both NRASG12V, with variant allele frequencies (VAF) of 0.3585 and 0.0300 respectively. In addition, the case 1 was also accompanied by an insertion mutation of ASXL1 D821 with a VAF of 0.3585 . The reexamination results on the third month showed that the MLL-SEPT6 gene remained positive but its expression level dropped from 100-24.4\%. The ASXL1 D821 VAF dropped to 0.0068 and NRASG12V gene mutation was not detected. Four month later, the patient achieved complete remission (CR), the ASXL1 D821 VAF dropped to 0.0032 and this time both the NRAS mutation and MLL-SEPT6 fusion gene were negative. The NRASA146T mutation in the case 3 occurred in exon 4 with a VAF of 0.4411 . MLL-SEPT6 gene and NRAS gene mutations both turned negative on the ninth month after diagnosis. The patient relapsed on the twenty-seventh month with positive MLL-SEPT6 and NRASA146T mutation (VAF $=0.2662)$. In the case 4, no pathogenic gene mutations were detected.

\section{Clinical Course}

The treatment and follow-up information of all cases (case 1-4) was shown in Table 1. Three cases (case 1-3) received chemotherapy, the case 2 subsequently received a bone marrow transplantation (BMT), the case 4 was a newborn and did not receive any chemotherapy. The clinical follow-up period ranges from 0.5 to 38 months with a median of 21.5 months. The case 1 initially received IA (idarubicin + cytosine arabinoside) regimens, which didn't make him reach CR. Then he began a new chemotherapy regime with decitabine combined with half dose CAG (cytarabine + aclacinomycin + granulocyte colony stimulating factor) and achieved CR. He also received an intrathecal injection (cytarabine + dexamethasone + methotrexate) for central nervous system infiltration prevention. After the chemotherapy, the bone marrow aspiration of the patient revealed a normal karyotype and negative molecular results of $M L L-S E P T 6$ rearrangement and NRAS mutation. The case 2 received MAE (mitoxantrone + cytarabine + etoposide) regimens and reached CR one month later. In the following six months, the patient received BMT. Nineteen months after the transplantation he was re-admitted for headache. A flow cytometry analysis of the cerebrospinal fluid revealed $81.9 \%$ leukemia cells which indicated central nervous system leukemia, following five courses of intrathecal injection, the child's headache relieved and no leukemia cells were detected in his cerebrospinal fluid. The case 3 received HA (homoharringtonine + cytarabine) regimens and intrathecal injection (cytarabine + dexamethasone + methotrexate), he reached CR four weeks after the diagnosis. This patient relapsed 27 months later, after receiving $\mathrm{HAl}$ (homoharringtonine + cytarabine + idarubicin) regimen he reached and remained CR status. The case 4 had dyspnea at birth, he was on assisted ventilation and given blood infusion to improve anemia and thrombocytopenia. The newborn's condition did not improve during the treatment. His parents refused the follow-up treatment, and the child died a week later.

\section{Literature review}

A total of 22 MLL-SEPT6 positive cases were included in this literature review, including four cases in our report and eighteen cases from literatures [6-16]. Table 2 and Table 3 listed the detailed laboratory results and clinical information of all cases. 
Table 3

Clinicopathologic features of evaluable patients

\begin{tabular}{|c|c|}
\hline Characteristic & $N(\%)$ \\
\hline Gender & $\mathrm{N}=22$ \\
\hline Male & $16(72.7 \%)$ \\
\hline Female & $6(27.3 \%)$ \\
\hline Age (years) & $\mathrm{N}=22$ \\
\hline$\leq 1$ & $12(54.5 \%)$ \\
\hline$>1$ and $<18$ & $8(36.4 \%)$ \\
\hline$\geq 18$ & $2(9.1 \%)$ \\
\hline WBC count $\left(\times 10^{9} / \mathrm{L}\right)$ & $\mathrm{N}=15$ \\
\hline$\geq 20.0$ & $9(60.0 \%)$ \\
\hline$<20.0$ & $6(40.0 \%)$ \\
\hline Symptom at presentation & $N=10$ \\
\hline Hepatosplenomegaly & $5(50.0 \%)$ \\
\hline CNS involvement & $3(30.0 \%)$ \\
\hline Lymphadenopathy & $3(30.0 \%)$ \\
\hline Skin involvement & $2(20.0 \%)$ \\
\hline FAB classification & $N=22$ \\
\hline M1 & $1(4.5 \%)$ \\
\hline M2 & $8(36.4 \%)$ \\
\hline M4 & $5(22.7 \%)$ \\
\hline M5 & $5(22.7 \%)$ \\
\hline Unknown & $3(13.6 \%)$ \\
\hline Chromosomal abnormalities & $N=22$ \\
\hline Translocations & $11(50.0 \%)$ \\
\hline Insertions & $9(40.9 \%)$ \\
\hline Complex abnormalities & $3(13.6 \%)$ \\
\hline Treatment protocol & $N=19$ \\
\hline Chemotherapy alone & $8(42.1 \%)$ \\
\hline BMT & $9(47.4 \%)$ \\
\hline No chemotherapy & $2(10.5 \%)$ \\
\hline Survival outcome & $\mathrm{N}=19$ \\
\hline Alive & $13(68.4 \%)$ \\
\hline Died & $6(31.6 \%)$ \\
\hline
\end{tabular}

The age of the patients ranged from 0 to 57 years (median $=1$ year), with a male-female ratio of nearly 3:1 (16 males vs. 6 females). Twenty patients ( $90.9 \%$ ) were children ( $\leq 9$ years old), including twelve $(54.5 \%)$ infants ( $\leq 1$ year old). The majority of the patients manifested leukocytosis (range $\left.1-608 \times 10^{9} / \mathrm{L}\right)$, anemia (range 41-109 g/L) and low platelet counts (range 9-254 × 10\%/L). According to the high WBC index [18], nine (60.0\%) of the fifteen cases with WBC count information were defined as high WBC levels. Twelve cases were not provided with description of clinical features. Of the remaining ten cases, five children (50.0\%) were observed of splenomegaly and hepatomegaly and three patients (30.0\%) had lymphadenopathy. Central nervous system involvement was observed in three children (30.0\%) and skin involvement was observed in two (20.0\%).

All patients were diagnosed with AML (twenty children and two adults) according to the former FAB classification: five patients (three children and two adults, $22.7 \%$ ) of M5, five children (22.7\%) of M4, eight children (36.4\%) of M2, one child (4.5\%) of M1, and three children (13.6\%) unknown. 
All the cases had available cytogenetic information, chromosomal translocations (eleven cases) were the most common chromosomal rearrangements, followed by chromosomal insertions (nine cases). Among them, Xq24 (nine cases) and 11q23 (fourteen cases) were the most frequently involved chromosomal bands. Seven cases (31.8\%) demonstrated complex abnormalities.

Of all 22 cases, 18 cases had clinical follow-up with median period of 27.7 months (0.5-101.5 months). Table 3 showed the clinicopathologic features of evaluable patients. Eight patients (42.1\%) received chemotherapy alone. Nine patients (50\%) received BMT. Six of eighteen patients died during the period of follow-up. Kaplan-Meier survival analysis was performed on eighteen cases with complete follow-up information (Figure 4A). As of the final follow-up, median survival time has not been reached. In order to understand the impact of age and BMT on survival time, the patients were divided into infant group ( $\leq 1$ year old, $n=10$ ), pediatric group ( $>1$ and $<18$ years old, $n=7$ ), and adult group ( $\geq 18$ years old, $n=1$ ). At the time of the last observation, there was no statistically significant differences in survival time between infant group and pediatric group (hazard ratio for infant-pediatric $=0.26,95 \%$ confidence interval $=0.07$ to $1.67, P=0.1822$, Figure $4 \mathrm{~B}$ ). The adult group was not included in the statistical analysis because there was only one case with complete follow-up information in this group. Meanwhile, the patients were also divided into receiving chemotherapy alone $(n=6$, one without survival information was excluded) and receiving BMT $(n=9)$ treatment groups according to the treatment protocol. Survival time between the patients received chemotherapy alone and BMT did not show significant differences neither (hazard ratio for chemotherapy alone-BMT $=1.04,95 \%$ confidence interval $=0.18$ to $6.19, P=0.9647$, Figure $4 \mathrm{C}$ ).

\section{Discussion}

The $M L L$ gene is a frequent target of rearrangement in human leukemia, especially in infant and pediatric leukemia $[9,19,20]$. It is well established that the rearrangement heralds poor prognosis $[5,21]$. These rearrangements include fusions with many partner genes, but rarely involve the X chromosome. SEPT6 is a member of the septin family of GTPases. Members of this family are involved in cell polarity, cytokinesis and oncogenesis [22, 23]. The $M L L$ gene and SEPT6 gene are vulnerable to damage to form translocations associated with infant AML.

In this study, we described four cases of AML with MLL-SEPT6 fusion gene. The FAB subtypes were mainly M2, M4 and M5, which was consistent with literatures. Most cases that have been reported were children. As far as we know, only two adult patients have been reported including one case in our series and $54.5 \%$ (12/22) were infant patients ( $\leq 1$ year old). Among these cases, $60.0 \%$ were with high level of WBC, and $30 \%$ manifested central nervous system involvement, which were similar to the clinical features of $M L L$-rearranged AML patients. The findings of Balgobind BV et al. showed that $M L L$-rearranged AML patients usually exhibit high tumor burden, including organomegaly, high median WBC and central nervous system involvement [24]. The present study included the largest number of MLL-SEPT6 cases to date. The patients' NGS test results were not provided except ours, and we also tracked the patients' molecular biological examination results. Three of four cases in our series occurred NRAS mutation while the rest one with congenital AML did not.

The NRAS mutations has very important roles in pathogenesis and progression of human leukemia, which have been frequently reported in AML patients [25, 26]. NRASG12V is required in leukemia self-renewal process, independent of its effects on growth and survival [27]. Compared with other subtypes of leukemia, acute leukemia with $M L L$-translocations (such as MLL-AF4 and MLL-AF9) harbored the fewest number of mutations, in which NRAS mutations commonly co-occur $[27,28]$. In our series, we identified NRAS mutations in MLL-SEPT6 positive AML patients for the first time, and most of the mutation sites appeared at codon 12 and 145. The former site is a hotspot mutant of NRAS and the latter site has also been reported [25, 29]. The VAF of NARS mutation decreased as the patients condition improved. When the patients achieved CR, it also turned negative. The underlying connection between NRAS mutations and MLL-SEPT6 and whether non-congenital MLL-SEPT6-positive AML patients all have NRAS mutations remain to be further studied in a larger cohort in the future.

$M L L$ gene rearrangement in AML usually indicates poor prognosis. The prognostic significance of NRASmutations in AML patients remains unclear [30-33]. Of the four cases in our series, one developed drug-resistant at first, one suffered relapse after BMT and one died, showing unsatisfactory therapeutic effect. However, whether the outcomes of patients with MLL-SEPT6 were aggravated by the concurrence of NRAS mutations needs a follow-up study. Kaplan-Meier curve demonstrated that pediatric group ( $>1$ and $<18$ years old) did not show better survival time compared with infant group ( $\leq 1$ year old). Age may not be an independent prognostic factor for survival. Most of the patients received chemotherapy, nine of them received BMT, but three of them eventually died. The survival time of patients between the chemotherapy alone group and the BMT group did not show a significant difference, which suggested that BMT may not improve the survival time of such patients. This was consistent with several studies and meta-analyses that suggesting BMT does not improve survival in patients with $M L L$ rearrangement [34,35]. But the prognosis and its factors of $M L L-S E P T 6$-positive AML patients need further analysis in more cases.

Our study has some limitations. Firstly, this was a retrospective study, coupled with limited number of reported cases and incomplete clinical information, which makes it impossible for us to obtain the median survival time of patients through statistical methods. On the other hand, the small sample sizes of some subgroups may lead to false negative results. Secondly, our NGS detection only covers the twenty most frequently mutated genes in AML, and prognostic effects of some critical genes may be neglected. Thirdly, gene mutation information in the reported cases was not available and cases in our series are detailed but limited by sample size. Therefore, our findings need to be combined with more cases to further explore the correlation between $M L L-S E P T 6$ and NRAS mutations.

\section{Conclusions}

In conclusion, the MLL-SEPT6 fusion gene was more commonly observed in pediatric patients diagnosed with AML. NRAS mutations were observed in these patients, most frequently of the NRASG12V hotspot mutation. Whether NRAS mutations are related to the occurrence of MLL-SEPT6-positive AML is currently unclear. The prognosis was inconclusive and may not be related to age. BMT may not improve survival in these patients. More cases should be accumulated and summarized to better understand the profile in MLL-SEPT6-positive AML. Our findings provide a basis for better understanding the mechanisms of leukemogenesis and the development of potential therapeutic targets for MLL-SEPT6-positive AML. 


\section{Abbreviations}

AML: acute myeloid leukemia

BMT: bone marrow transplantation

WHO: World Health Organization

WBC: white blood cells

FAB: French American British

NGS: next-generation sequencing

VAF: variant allele frequency

CR: complete remission

IA: idarubicin + cytosine arabinoside

CAG: cytarabine + aclacinomycin + granulocyte colony stimulating factor

MAE: mitoxantrone + cytarabine + etoposide

HA: homoharringtonine + cytarabine

HAl: homoharringtonine + cytarabine + idarubicin

CNS: central nervous system

Hb: hemoglobin

PLT: platelets

LDH: lactate dehydrogenase

NA: not available

\section{Declarations}

\section{Ethics approval and consent to participate}

This study was conducted according to the guidelines of the Declaration of Helsinki, and approved by the Ethics Committee of Shengjing Hospital of China Medical University (No. 2021PS122K). All patients provided written informed consents.

\section{Availability of data and materials}

The datasets during and/or analyzed during the current study available from the corresponding author on reasonable request

\section{Consent for publication}

Written informed consent for publication of their clinical details and clinical images was obtained from the patient/parent of the patient.

\section{Competing interests}

The authors declare that they have no competing interests.

\section{Funding}

This work was supported by the National Natural Science Foundation of China (NSFC) (grant number: 82070165).

Author's contributions

Shuang Fu and Fang Chen performed study concept and design; Shuang Fu, Fang Chen and Ying Yang performed development of methodology and writing, review and revision of the paper; Fang Chen and Ying Yang provided acquisition, analysis and interpretation of data, and statistical analysis. All authors read and approved the final paper.

\section{Acknowledgments}

We thank Yue Zhao for his help in manuscript editing, and Yu Fu, Xuan Liu and Minyu Zhang for their expert technical assistance. All individuals referenced here have no publication related-funding source, industry-relation, or conflicts of interest. 


\section{References}

1. Culp-Hill R, D'Alessandro A, Pietras EM. Extinguishing the Embers: Targeting AML Metabolism. Trends Mol Med. 2021;27(4):332-344. doi: 10.1016/j.molmed.2020.10.001

2. De Kouchkovsky I, Abdul-Hay M. Acute myeloid leukemia: a comprehensive review and 2016 update. Blood Cancer J. 2016;6(7):e441. doi: 10.1038/bcj.2016.50

3. Matsuo H, Yoshida K, Fukumura K, Nakatani K, Noguchi Y, Takasaki S, et al. Recurrent CCND3 mutations in MLL-rearranged acute myeloid leukemia. Blood Adv. 2018;2(21):2879-2889. doi: 10.1182/bloodadvances.2018019398

4. Wander P, Arentsen-Peters STCJM, Pinhanços SS, Koopmans B, Dolman MEM, Ariese R, et al. High-throughput drug screening reveals Pyrvinium pamoate as effective candidate against pediatric MLL-rearranged acute myeloid leukemia. Transl Oncol. 2021;14(5):101048. doi: 10.1016/j.tranon.2021.101048

5. Meyer C, Burmeister T, Gröger D, Tsaur G, Fechina L, Renneville A, et al. The MLL recombinome of acute leukemias in 2017. Leukemia. 2018;32(2):273284. doi: $10.1038 /$ leu.2017.213

6. Ono R, Taki T, Taketani T, Kawaguchi H, Taniwaki M, Okamura T, et al. SEPTIN6, a human homologue to mouse Septin6, is fused to MLL in infant acute myeloid leukemia with complex chromosomal abnormalities involving 11q23 and Xq24. Cancer Res. 2002;62(2):333-337. PMID: 31865373

7. Borkhardt A, Teigler-Schlegel A, Fuchs U, Keller C, König M, Harbott J, et al. An ins(X;11)(q24;q23) fuses the MLL and the Septin 6/KIAA0128 gene in an infant with AML-M2. Genes Chromosomes Cancer. 2001;32:82-88. doi: 10.1002/gcc.1169

8. Slater DJ, Hilgenfeld E, Rappaport EF, Shah N, Meek RG, Williams WR, et al. MLL-SEPTIN6 fusion recurs in novel translocation of chromosomes 3, X, and 11 in infant acute myelomonocytic leukaemia and in $\mathrm{t}(\mathrm{X} ; 11)$ in infant acute myeloid leukaemia, and MLL genomic breakpoint in complex MLL-SEPTIN6 rearrangement is a DNA topoisomerase II cleavage site. Oncogene. 2002;21(30):4706-4714. doi: 10.1038/sj.onc.1205572

9. Kim HJ, Ki CS, Park Q, Koo HH, Yoo KH, Kim EJ, et al. MLL/SEPTIN6 chimeric transcript from inv ins(X;11)(q24;q23q13) in acute monocytic leukemia: report of a case and review of the literature. Genes Chromosomes Cancer. 2003;38(1):8-12. doi: 10.1002/gcc.10235

10. Fu JF, Liang DC, Yang CP, Hsu JJ, Shih LY. Molecular analysis of $t(X ; 11)(q 24 ; q 23)$ in an infant with AML-M4. Genes Chromosomes Cancer. 2003;38(3):253-259. doi: 10.1002/gcc.10272

11. Harrison C. J., Cuneo A., Clark R., Johansson B., Lafage-Pochitaloff M., Mugneret F., et al. Ten novel 11q23 chromosomal partner sites. European 11q23 Workshop participants. Leukemia (Baltimore). 1998;12(5):811-822. doi: 10.1038/sj.leu.2401017

12. Nakata Y., Mori T., Yamazaki T., Suzuki T., Okazaki T., Kurosawa Y., et al. Acute myeloid leukemia with hypergranular cytoplasm accompanied by $t(X ; 11)$ (q24;q23) and rearrangement of the MLL gene. Leuk Res. 1999;23(1):85-88. doi: 10.1016/s0145-2126(98)00131-3

13. Cerveira N, Lisboa S, Correia C, Bizarro S, Santos J, Torres L, et al. Genetic and clinical characterization of 45 acute leukemia patients with MLL gene rearrangements from a single institution. Mol Oncol. 2012;6(5):553-564. doi: 10.1016/j.molonc.2012.06.004

14. De Braekeleer E, Meyer C, Douet-Guilbert N, Basinko A, Le Bris MJ, Morel F, et al. Identification of MLL partner genes in 27 patients with acute leukemia from a single cytogenetic laboratory. Mol Oncol. 2011;5(6):555-563. doi: 10.1016/j.molonc.2011.08.003

15. Cerveira N, Micci F, Santos J, Pinheiro M, Correia C, Lisboa S, et al. Molecular characterization of the MLL-SEPT6 fusion gene in acute myeloid leukemia: identification of novel fusion transcripts and cloning of genomic breakpoint junctions. Haematologica. 2008;93(7):1076-1080. doi: $10.3324 /$ haematol.12594

16. Kadkol SS, Bruno A, Oh S, Schmidt ML, Lindgren V. MLL-SEPT6 fusion transcript with a novel sequence in an infant with acute myeloid leukemia. Cancer Genet Cytogenet. 2006:68(2):162-167. doi: 10.1016/j.cancergencyto.2006.02.020

17. Arber DA, Brunning RD, Le Beau MM, et al. Acute myeloid leukaemia and related precursor neoplasms. In: Swerdlow SH, Campo E, Harris NL, et al., editors. WHO classification of tumours of haematopoietic and lymphoid tissues. Revised 4th edition. France: IARC Press; 2017. p.130-171.

18. Nguyen S, Leblanc T, Fenaux P, Witz F, Blaise D, Pigneux A, et al. A white blood cell index as the main prognostic factor in $t(8 ; 21)$ acute myeloid leukemia (AML): a survey of 161 cases from the French AML Intergroup. Blood. 2002;99(10):3517-3523. doi: 10.1182/blood.v99.10.3517.

19. Antunes ETB, Ottersbach K. The MLL/SET family and haematopoiesis. Biochim Biophys Acta Gene Regul Mech. 2020;1863(8):194579. doi: 10.1016/j.bbagrm.2020.194579

20. Rice S, Roy A. MLL-rearranged infant leukaemia: A 'thorn in the side' of a remarkable success story. Biochim Biophys Acta Gene Regul Mech 2020;1863(8):194564. doi: 10.1016/j.bbagrm.2020.194564

21. Wong NM, So CWE. Novel therapeutic strategies for MLL-rearranged leukemias. Biochim Biophys Acta Gene Regul Mech. 2020;1863(9):194584. doi: 10.1016/j.bbagrm.2020.194584.

22. Ivanov Al, Le HT, Naydenov NG, Rieder F. Novel Functions of the Septin Cytoskeleton: Shaping Up Tissue Inflammation and Fibrosis. Am J Pathol. 2021; 191(1):40-51. doi: 10.1016/j.ajpath.2020.09.007

23. Macara IG, Baldarelli R, Field CM, Glotzer M, Hayashi Y, Hsu SC, et al. Mammalian septins nomenclature. Mol Biol Cell. 2002;13(12):4111-4113. doi: 10.1091/mbc.e02-07-0438

24. Balgobind BV, Zwaan CM, Pieters R, Van den Heuvel-Eibrink MM. The heterogeneity of pediatric MLL-rearranged acute myeloid leukemia. Leukemia. 2011;25(8):1239-1248. doi: 10.1038/leu.2011.90.

25. Bacher U, Haferlach T, Schoch C, Kern W, Schnittger S. Implications of NRAS mutations in AML: a study of 2502 patients. Blood. 2006;107(10):3847-3853. doi: 10.1182/blood-2005-08-3522

26. Pomeroy EJ, Lee LA, Lee RDW, Schirm DK, Temiz NA, Ma J, et al. Ras oncogene-independent activation of RALB signaling is a targetable mechanism of escape from NRAS(V12) oncogene addiction in acute myeloid leukemia. Oncogene. 2017;36(23):3263-3273. doi: 10.1038/onc.2016.471

Page $8 / 12$ 
27. Sachs Z, LaRue RS, Nguyen HT, Sachs K, Noble KE, Mohd Hassan NA, et al. NRASG12V oncogene facilitates self-renewal in a murine model of acute myelogenous leukemia. Blood. 2014;124(22):3274-3283. doi: 10.1182/blood-2013-08-521708

28. Trentin L, Bresolin S, Giarin E, Bardini M, Serafin V, Accordi B, et al. Deciphering KRAS and NRAS mutated clone dynamics in MLL-AF4 paediatric leukaemia by ultra deep sequencing analysis. Sci Rep. 2016;6:34449. doi: 10.1038/srep34449

29. Wang S, Wu Z, Li T, Li Y, Wang W, Hao Q, et al. Mutational spectrum and prognosis in NRAS-mutated acute myeloid leukemia. Sci Rep. $2020 ; 10(1): 12152$. doi: 10.1038/s41598-020-69194-6

30. Welch JS, Ley TJ, Link DC, Miller CA, Larson DE, Koboldt DC, et al. The origin and evolution of mutations in acute myeloid leukemia. Cell. 2012;150(2):264278. doi: 10.1016/j.cell.2012.06.023

31. Liu X, Ye Q, Zhao XP, Zhang PB, Li S, Li RQ, et al. RAS mutations in acute myeloid leukaemia patients: A review and meta-analysis. Clin Chim Acta. 2019; 489:254-260. doi: 10.1016/j.cca.2018.08.040

32. Damm F, Heuser M, Morgan M, Wagner K, Görlich K, Grosshennig A, et al. Integrative prognostic risk score in acute myeloid leukemia with normal karyotype. Blood. 2011;117(17):4561-4568. doi: 10.1182/blood-2010-08-303479

33. Sano H, Shimada A, Taki T, Murata C, Park MJ, Sotomatsu M, et al. RAS mutations are frequent in FAB type M4 and M5 of acute myeloid leukemia, and related to late relapse: a study of the Japanese Childhood AML Cooperative Study Group. Int J Hematol. 2012;95(5):509-515. doi: 10.1007/s12185-0121033-x

34. Winters AC, Bernt KM. MLL-Rearranged Leukemias-An Update on Science and Clinical Approaches. Front Pediatr. 2017;5:4. doi: 10.3389/fped.2017.00004

35. Balgobind BV, Raimondi SC, Harbott J, Zimmermann M, Alonzo TA, Auvrignon A, et al. Novel prognostic subgroups in childhood 11q23/MLL-rearranged acute myeloid leukemia: results of an international retrospective study. Blood. 2009;114(12):2489-2496. doi: 10.1182/blood-2009-04-215152

\section{Table}

Due to technical limitations, table 2 docx is only available as a download in the Supplemental Files section.

\section{Figures}

A

$\mathrm{BM}$

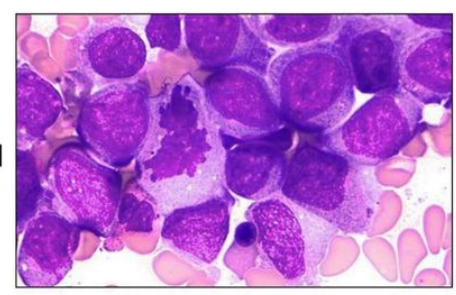

$\mathrm{PB}$

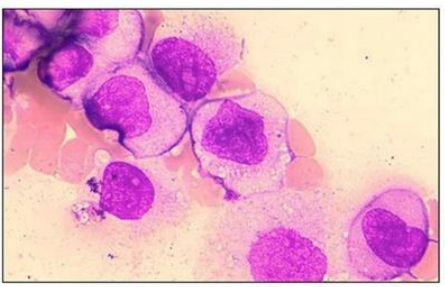

C

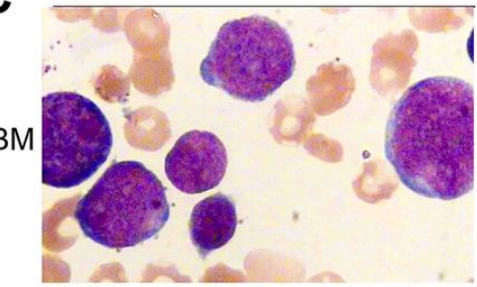

PB

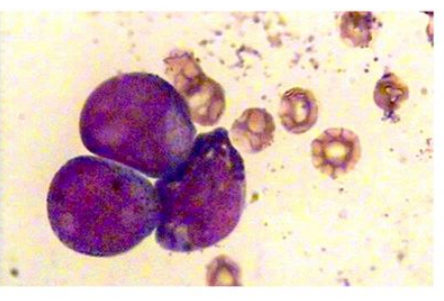

B
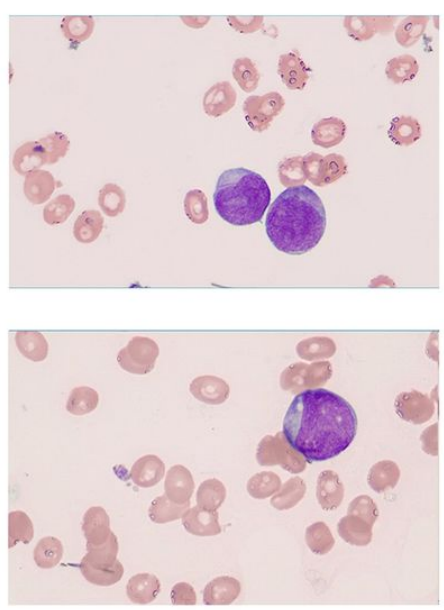

D
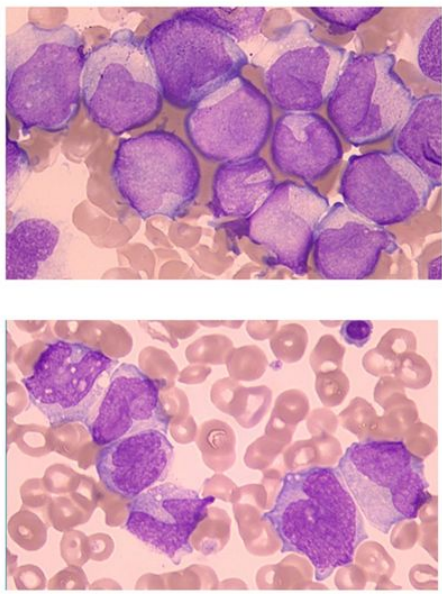
Figure 1

Morphologic evaluation of leukemic cells at diagnosis (Wright-Giemsa stain, $\times 1000)$. (A), (B), (C) and (D) represented the case 1, 2, 3 and 4, respectively. BM, bone marrow; PB, peripheral blood.

A
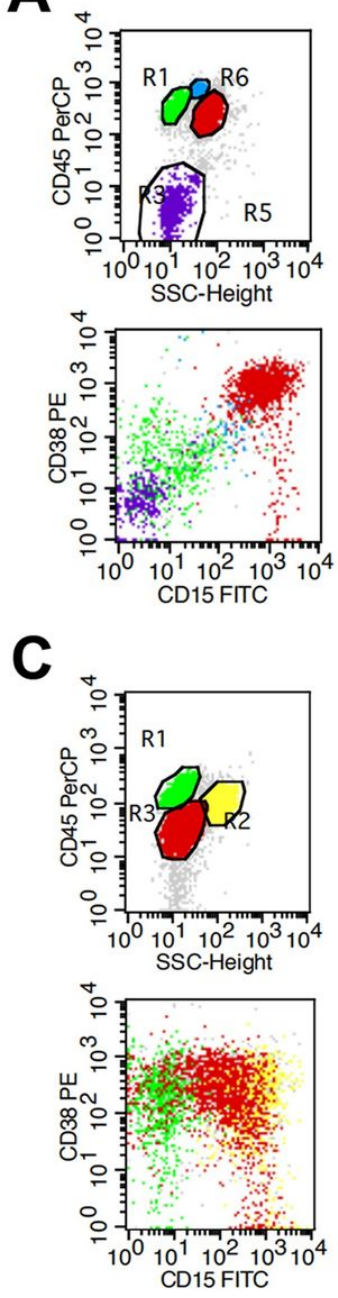
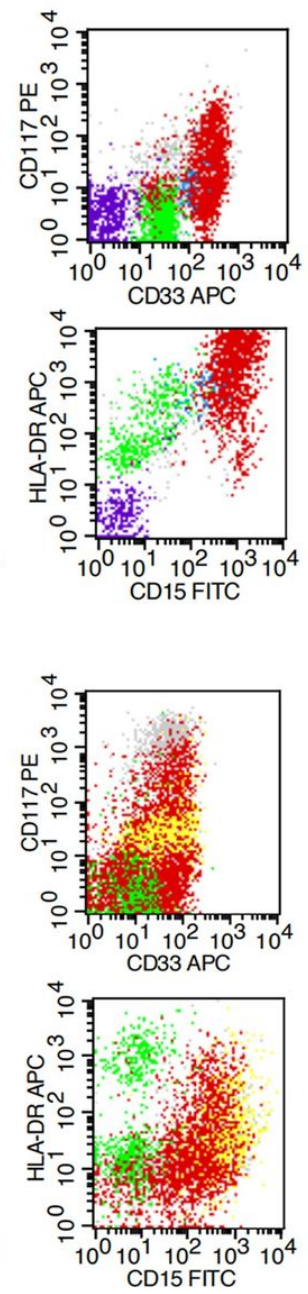

B
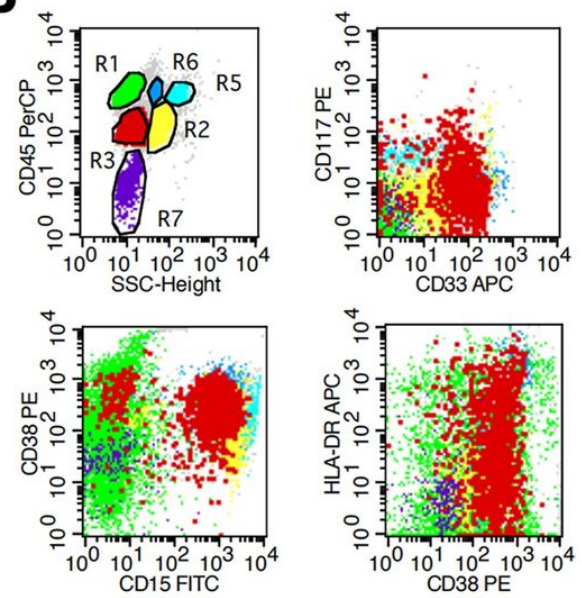

D
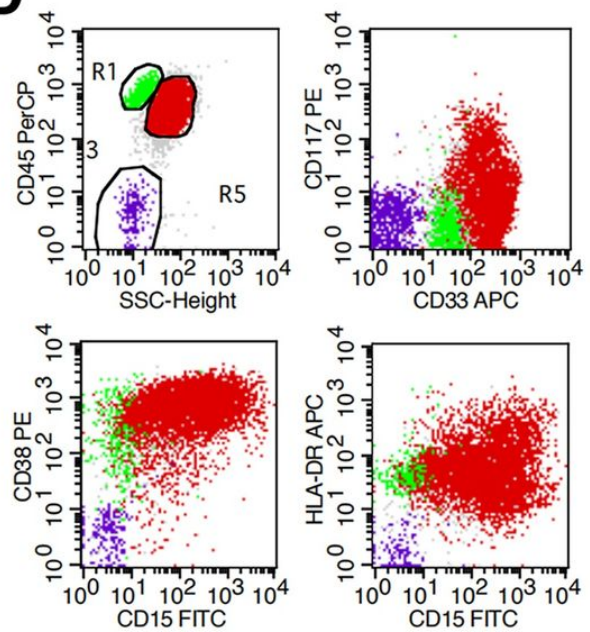

Figure 2

Flow cytometry results of bone marrow. (A), (B), (C) and (D) represented the case 1, 2, 3 and 4, respectively. 
A

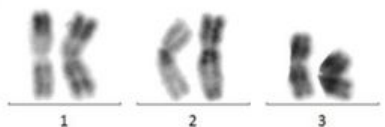

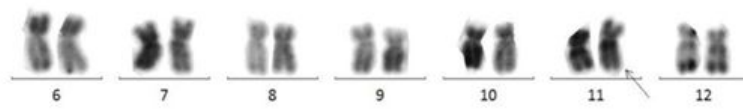

Af 18 if

है

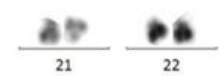

C

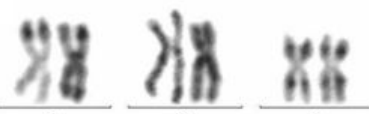

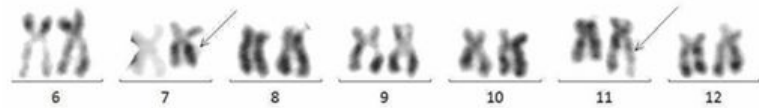

$\mathrm{An}$ An $\frac{\mathrm{An}}{\mathrm{is}} \quad \mathrm{xh}$ an $\mathrm{an}$
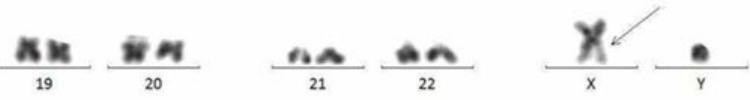

B

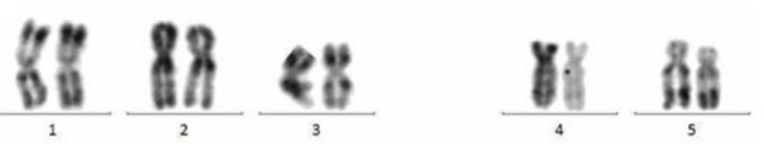

\section{8 .}
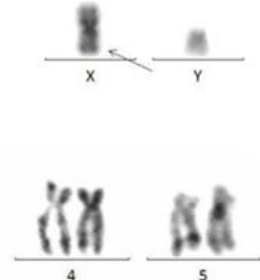

$\mathrm{D}$

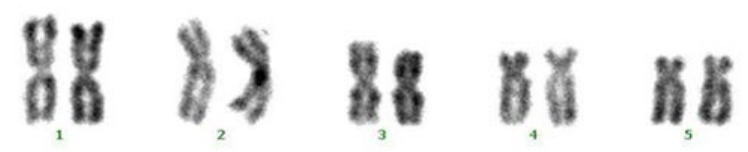

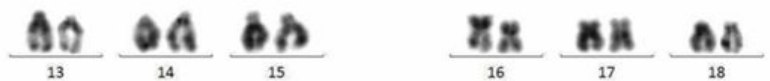

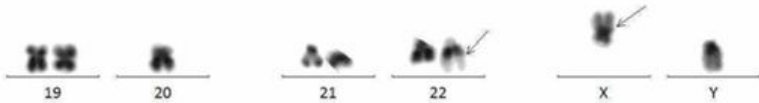

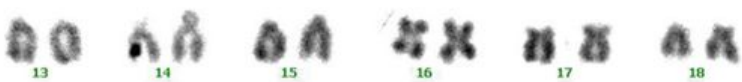

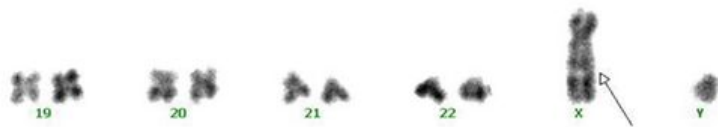

Figure 3

Karyotype analysis results of bone marrow. (A), (B), (C) and (D) represented the case 1, 2, 3 and 4, respectively.
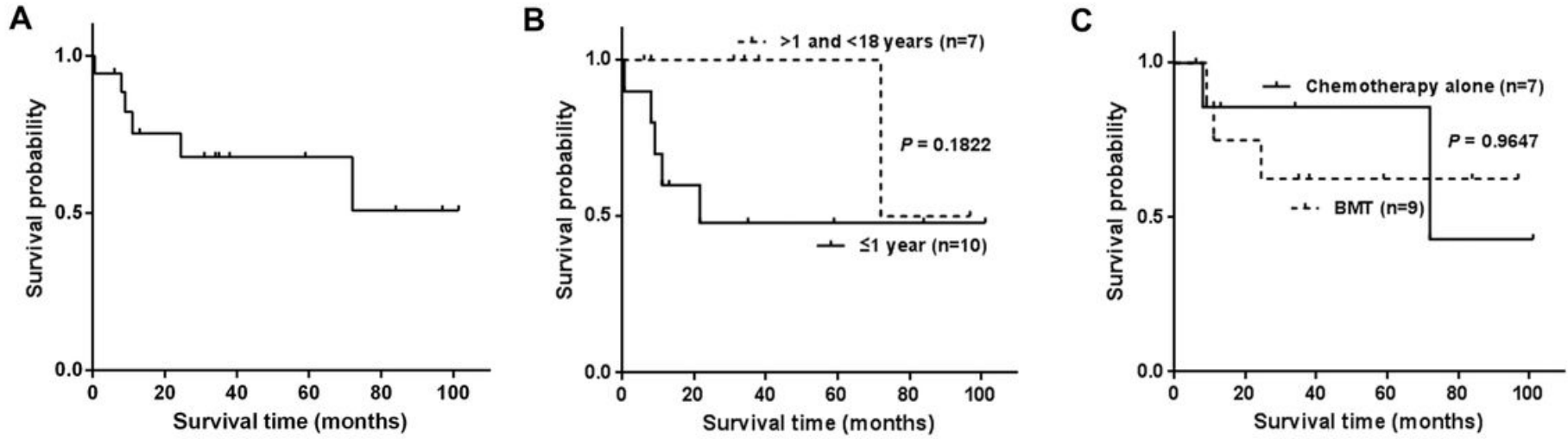

Figure 4

Kaplan-Meier survival analysis of eighteen cases with complete follow-up information. These included fourteen reported cases with clinical follow-up, and four cases in our series. (A) Survival months of eighteen cases. (B) Infant group ( $\leq 1$ year) vs. pediatric group ( $>1$ and $<18$ years old). Hazard ratio for infantpediatric $=0.26,95 \%$ confidence interval $=0.07$ to $1.67, \mathrm{P}=0.1822$. (C) Chemotherapy alone vs. BMT. Hazard ratio for chemotherapy alone-BMT $=1.04,95 \%$ confidence interval $=0.18$ to $6.19, \mathrm{P}=0.9647$.

\section{Supplementary Files}


This is a list of supplementary files associated with this preprint. Click to download.

- Table2.doc

Page 12/12 